\title{
Associação de carboidrases e fitase em dietas valorizadas e seus efeitos sobre desempenho e qualidade dos ovos de poedeiras leves
}

\author{
[Association of carbohydrases and phytase in enriched diets ranked and its effects on \\ performance and quality of eggs from light laying hens] \\ C.B. Ferreira ${ }^{1}$, A. Geraldo ${ }^{2}$, J.A. Vieira Filho ${ }^{3}$, J.A.G. Brito ${ }^{4}$, \\ A.G. Bertechini ${ }^{5}$, S.R.F. Pinheiro ${ }^{6}$ \\ ${ }^{1}$ Universidade Federal de Minas Gerais - UFMG - Belo Horizonte, MG \\ ${ }^{2}$ Instituto Federal de Ciência e Tecnologia de Minas Gerais - IFMG -Bambuí, MG \\ ${ }^{3}$ Universidade Estadual Paulista "Júlio de Mesquita Filho" - UNESP - Botucatu, SP \\ ${ }^{4}$ Universidade Federal do Recôncavo da Bahia - UFRB - Cruz das Almas, BA \\ ${ }^{5}$ Universidade Federal de Lavras - UFLA - Lavras, MG \\ ${ }^{6}$ Universidade Federal dos Vales do Jequitinhonha e Mucuri - UFVJM - MG
}

\begin{abstract}
RESUMO
Foram utilizadas 350 aves da linhagem comercial Bovans White, com o objetivo de avaliar a associação de carboidrases e fitase em dietas valorizadas sobre o desempenho e qualidade dos ovos de poedeiras leves. O delineamento experimental foi inteiramente ao acaso, com 5 tratamentos e 7 repetições. Os tratamentos foram: T1- Controle positivo sem adição de enzimas e sem valorização dos nutrientes; T2Controle negativo $(\mathrm{CN}) 1$, valorizando em $1,5 \%$ e $6 \%$ a EMA $(\mathrm{kcal} / \mathrm{kg})$, respectivamente para o milho e o farelo de soja, e em $2 \%$ a proteína bruta (PB) e os aminoácidos digestíveis limitantes mais a matriz completa para a enzima fitase; T3- CN 2, valorizando em $1,5 \%$ e $6 \%$ a EMA (kcal/kg), respectivamente para o milho e o farelo de soja, e em $2 \%$ a proteína bruta (PB) e os aminoácidos digestíveis limitantes mais a matriz incompleta para a enzima fitase; T4- suplementado com $100 \mathrm{~g} \mathrm{ton}^{-1}$ de carboidrase e $30 \mathrm{~g}$ ton $^{-1}$ de fitase; T5- suplementado com $100 \mathrm{~g} \mathrm{ton}^{-1}$ de carboidrase e $30 \mathrm{~g} \mathrm{ton}^{-1}$ de fitase. Os tratamentos controle positivo, T2, T3, T4 e T5, com ou sem suplementação enzimática, garantiram o desempenho no que diz respeito ao consumo de ração, produção, peso e perdas de ovos e qualidade da casca.
\end{abstract}

Palavras-chave: enzimas, galinhas poedeiras, nutrição

\begin{abstract}
A total of 350 commercial Bovans White laying hens were used to evaluate the association of carbohydrases and phytase in enriched diets and its effects on performance and egg quality of laying hens. The experiment used a randomized design with five treatments and seven replicates. The treatments were: 1. Positive control without added enzymes and without nutrient enrichment, 2. Negative control (NC) 1 with $1.5 \%$ and $6 \%$ AME (kcal/kg) enrichment for corn and soybean meal respectively, $2 \%$ crude protein (CP) enrichment, and digestible limiting digestible amino acids plus the full matrix for the phytase enzyme; 3. NC 2 with $1.5 \%$ and 6\% AME (kcal/kg) enrichment, respectively, for corn and soybean meal and $2 \%$ crude protein $(C P)$ enrichment, and digestible limiting amino acids plus the sparse matrix for the phytase enzyme, 4. NC 1 supplemented with $100 \mathrm{~g}_{\text {ton }}^{-1}$ carbohydrase and $30 \mathrm{~g} \mathrm{ton}^{-1}$ phytase, 5. NC 2 supplemented with $100 \mathrm{~g} \mathrm{ton}^{-1}$ carbohydrase and $30 \mathrm{~g} \mathrm{ton}{ }^{-1}$ phytase. According to the results, the positive control treatments, $\mathrm{NCl}$ and NC2, with or without enzyme supplementation, showed guaranteed performance for feed intake, egg yield, weight, egg loss and shell quality.
\end{abstract}

Keywords: enzymes, laying hens, nutrition

Recebido em 22 de julho de 2013

Aceito em 7 de agosto de 2014

E-mail: catialp@hotmail.com

Apoio financeiro: FAPEMIG 


\section{INTRODUÇÃO}

Com o crescente avanço em produção de alimento de alto valor biológico para alimentação humana, a avicultura de postura tem contribuído e se adequado às novas tecnologias que possibilitam a melhoria da produção das aves e menor custo de produção de ovos para atender à demanda da população. A partir desse momento, passou-se a utilizar maiores quantidades de ingredientes de origem vegetal em substituição aos de origem animal com o intuito de minimizar custos e aumentar a eficiência da ração (Viana et al., 2009). No entanto, esses ingredientes possuem fatores antinutricionais e/ou substâncias que não são normalmente digeridas pelas enzimas digestivas, diminuindo assim o aproveitamento desses compostos.

O fitato, ou ácido fítico, é a principal forma de armazenamento do fósforo nos grãos de cereais, leguminosas e oleaginosas. Além de indisponibilizá-lo, o ácido fítico reduz a biodisponibilidade de minerais, como cálcio, zinco, ferro, magnésio e nutrientes, como aminoácidos e lipídeos (Snow et al., 2002). Para atender às exigências de fósforo dos animais, fontes inorgânicas, como os fosfatos, são adicionadas às dietas. Porém, o excesso de suplementação, além de aumentar os custos da dieta, aumenta também os teores de fósforo e nitrogênio nas excretas das aves, poluindo o solo, as águas de rios, lagos, oceanos e contribuindo assim para a eutrofização dos sistemas aquáticos (Liu et al., 2006).

A utilização de enzimas exógenas (amilase, protease, lipase, xilanase, fitase etc.) surgiu como uma alternativa para aumentar o valor nutritivo de ingredientes alimentares que possuem baixos coeficientes de digestibilidade e apresentam significativa fração de polissacarídeos não amiláceos (PNA's) estruturais e/ou fatores antinutricionais. Esses nutrientes não são hidrolisados pelas enzimas digestivas, aumentando a viscosidade da dieta e tornando-a menos digestível (Mazzuco, 2008).

A inclusão da enzima fitase na ração de poedeiras é uma das maneiras de aumentar a disponibilidade do fósforo de origem vegetal e, consequentemente, diminuir a quantidade de fósforo inorgânico na ração, o que minimiza os efeitos ambientais provocados pelo excesso de fósforo nas excretas. Além disso, a fitase também afeta a biodisponibilidade de outros elementos, principalmente os cátions bivalentes que podem estar quelatados na molécula de fitato (Plumstead et al., 2007).

Já o uso de carboidrases específicas, produzidas por fungos do gênero Aspergillus, tem sido adotado para hidrolisar os polissacarídeos não amiláceos, aumentando a digestibilidade de ingredientes fibrosos, além de aumentar $\mathrm{o}$ aproveitamento da energia por liberar nutrientes ricos em energia, tanto da estrutura fibrosa dos PNA's insolúveis como do gel viscoso formado pelos PNA's solúveis (Conte et al., 2003).

Dessa forma, o presente trabalho teve como objetivo avaliar os efeitos da associação de carboidrases e fitase em dietas valorizadas para poedeiras leves e seus efeitos sobre $\mathrm{o}$ desempenho e qualidade dos ovos.

\section{MATERIAL E MÉTODOS}

Foram utilizadas 350 poedeiras leves da linhagem Bovans White, com 35 semanas de idade, alojadas durante o período de produção em galpão de postura, com telas na lateral e coberto com telhas de cerâmica em duas águas.

$\mathrm{O}$ delineamento experimental utilizado foi inteiramente ao acaso (DIC), em esquema de parcela subdividida (5 períodos experimentais de 21 dias cada), composto por cinco tratamentos e sete repetições por parcela, sendo cada parcela constituída de cinco gaiolas de arame galvanizado, com capacidade para duas aves cada, totalizando dez aves por parcela.

Os tratamentos utilizados foram:

T1 - Ração Controle Positivo 1 (CP1): 2.780 kcal EM $\mathrm{kg}^{-1}, 16,26 \% \mathrm{~PB}, 3,80 \%$ de cálcio $(\mathrm{Ca}), 0,34 \%$ de fósforo disponível (Pd), sem a adição de enzimas e sem valorização dos nutrientes;

T2 - Ração Controle Negativo 1 (CN1): $2.751 \mathrm{kcal}$

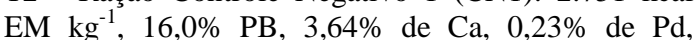
valorizando em 1,5 e $6 \%$ a EMA (kcal $\mathrm{kg}^{-1}$ ), respectivamente do milho e o farelo de soja, e em $2 \%$ a proteína bruta $(\mathrm{PB})$ e os aminoácidos digestíveis limitantes (Met, Met+Cis, Lis, Thr, Trp, Val e I) e redução nos níveis nutricionais conforme matriz completa para a enzima fitase $($ EMAn $=1.000 .000$, $\mathrm{PB}=8.000, \mathrm{Ca}=5.000, \mathrm{Pd}=4.000, \mathrm{Met}=145$, Met+Cis $=280$, Lis $=380 \mathrm{e} \mathrm{Thr}=260$ ), sem a adição de enzimas; 
T3 - Ração Controle Negativo 2 (CN2), 2.781 kcal EM $\mathrm{kg}^{-1}, 16,26 \% \mathrm{~PB}, 3,64 \%$ de $\mathrm{Ca}, 0,23 \%$ de $\mathrm{Pd}$, valorizando em 1,5 e $6 \%$ a EMA (kcal $\mathrm{kg}^{-1}$ ), respectivamente do milho e o farelo de soja, e em $2 \%$ a proteína bruta $(\mathrm{PB})$ e os aminoácidos digestíveis limitantes mais a matriz incompleta para a enzima fitase, sem adição de enzimas;

$\mathrm{T} 4$ - Ração suplementada com $100 \mathrm{~g} \mathrm{t}^{-1}$ de carboidrases (Alfa-galactosidase: $35 \mathrm{U} \mathrm{g}^{-1}$; Galactomananase: 110 U g-1; Beta-glucanase: $1.100 \mathrm{U} \mathrm{g}^{-1}$; Xilanase: $1.500 \mathrm{U}$ $\left.\mathrm{g}^{-1}\right)$ e $30 \mathrm{~g} \mathrm{t}^{-1}$ de fitase (10.000 FTU g $\left.{ }^{-1}\right)$, valorizando proteína, energia e aminoácidos;
T5 - Ração suplementada com $100 \mathrm{~g} \mathrm{t}^{-1}$ de carboidrases e $30 \mathrm{~g} \mathrm{t}^{-1}$ de fitase, sem valorização dos nutrientes.

As rações experimentais foram formuladas à base de milho, farelo de soja e trigo, e a fonte de fósforo utilizada foi $\mathrm{o}$ fosfato bicálcico. Considerou-se a composição dos alimentos, segundo as recomendações de Rostagno et al. (2005) e as exigências de acordo o manual da linhagem (Product..., 2006). As composições percentuais e calculadas das rações experimentais encontram-se na Tab. 1.

Tabela 1. Composição percentual e calculada das rações experimentais de poedeiras comerciais

\begin{tabular}{|c|c|c|c|c|c|}
\hline Ingredientes & $\mathrm{T} 1$ & $\mathrm{~T} 2^{2}$ & $\mathrm{~T}^{3}$ & $\mathrm{~T} 4^{4}$ & $\mathrm{~T} 5^{5}$ \\
\hline Milho & 63,931 & 60,111 & 59,139 & 60,111 & 59,139 \\
\hline Farelo de soja & 23,6 & 20,6 & 21,5 & 20,6 & 21,5 \\
\hline Farelo de trigo & 0,83 & 8,97 & 8,48 & 8,97 & 8,48 \\
\hline Óleo de soja & 0,71 & 0 & 0,57 & 0 & 0,57 \\
\hline Fosfato bicálcico & 1,3 & 0,6 & 0,6 & 0,6 & 0,6 \\
\hline Calcário calcítico & 8,9 & 8,94 & 8,94 & 8,94 & 8,94 \\
\hline Sal comum & 0,33 & 0,33 & 0,33 & 0,33 & 0,33 \\
\hline Premix vitamínico $^{6}$ & 0,1 & 0,1 & 0,1 & 0,1 & 0,1 \\
\hline Premix mineral $^{7}$ & 0,1 & 0,1 & 0,1 & 0,1 & 0,1 \\
\hline Cloreto de colina $(60 \%)$ & 0,046 & 0,046 & 0,046 & 0,046 & 0,046 \\
\hline Dl-metionina & 0,153 & 1,42 & 0,145 & 0,142 & 0,145 \\
\hline $\mathrm{HCl}$-lisina & 0 & 0,01 & 0 & 0,01 & 0 \\
\hline L-treonina & 0 & 0,001 & 0 & 0,001 & 0 \\
\hline Caulim & 0 & 0,05 & 0,05 & 0,027 & 0,027 \\
\hline Complexo de Carboidrases & 0 & 0 & 0 & 0,02 & 0,02 \\
\hline Fitase & 0 & 0 & 0 & 0,003 & 0,003 \\
\hline Total & 100 & 100 & 100 & 100 & 100 \\
\hline \multicolumn{6}{|c|}{ Composição nutricional calculada das rações ${ }^{8}$} \\
\hline Proteína Bruta $(\%)$ & 16,26 & 16 & 16,26 & 16 & 16,26 \\
\hline Cálcio (\%) & 3,8 & 3,64 & 3,64 & 3,64 & 3,64 \\
\hline Fósforo Disponível (\%) & 0,34 & 0,23 & 0,23 & 0,23 & 0,23 \\
\hline Sódio $(\%)$ & 0,16 & 0,16 & 0,16 & 0,16 & 0,16 \\
\hline Energia Metabolizável $\left(\mathrm{kcal}^{1}\right)$ & 2780 & 2751 & 2781 & 2751 & 2781 \\
\hline Lisina Dig Aves (\%) & 0,735 & 0,723 & 0,736 & 0,723 & 0,736 \\
\hline Met+Cist Dig-Aves (\%) & 0,63 & 0,622 & 0,63 & 0,622 & 0,63 \\
\hline Triptofano Dig-Aves (\%) & 0,179 & 0,178 & 0,182 & 0,178 & 0,182 \\
\hline Treonina Dig-Aves $(\%)$ & 0,546 & 0,538 & 0,546 & 0,538 & 0,546 \\
\hline
\end{tabular}

${ }^{1}$ Recomendações do manual da linhagem Bovans White (Product..., 2006). ${ }^{2}$ Tratamento 2, (CN1) valorizando em $1,5 \%$ e $6 \%$ a EMA $(\mathrm{kcal} / \mathrm{kg})$, respectivamente para o milho e o farelo de soja, e em $2 \%$ a proteína bruta e os aminoácidos digestíveis limitantes mais a matriz completa para a enzima fitase $(\mathrm{EMAn}=1.000 .000, \mathrm{~PB}=8000, \mathrm{Ca}=$ $5000, \mathrm{Pd}=4000, \mathrm{Met}=145, \mathrm{Met}+\mathrm{Cis}=280, \mathrm{Lis}=380 \mathrm{e} \mathrm{Tre}=260) ;{ }^{3}$ Tratamento $3,(\mathrm{CN} 2)$ valorizando em $1,5 \% \mathrm{e}$ $6 \%$ a EMA $(\mathrm{kcal} / \mathrm{kg})$, respectivamente para o milho e o farelo de soja, e em $2 \%$ a proteína bruta (PB) e os aminoácidos digestíveis limitantes mais a matriz incompleta para a enzima fitase; ${ }^{4}$ Tratamento 4 , suplementado com $100 \mathrm{~g} /$ ton. de carboidrase e $30 \mathrm{~g} / \mathrm{ton}$. de fitase, valorizando proteína, energia e aminoácidos; ${ }^{5}$ Tratamento 5, suplementado com $100 \mathrm{~g} / \mathrm{ton}$. de carboidrase e $30 \mathrm{~g} / \mathrm{ton}$. de fitase, sem valorização dos nutrientes. ${ }^{6}$ Composição do premix mineral por kg de produto (níveis mínimos de garantia): manganês $75.000 \mathrm{mg}$, ferro $50.000 \mathrm{mg}$, iodo $1.500 \mathrm{mg}$, zinco $70.000 \mathrm{mg}$, cobre $8.500 \mathrm{mg}$, cobalto $200 \mathrm{mg}$; ${ }^{7}$ Composição do premix vitamínico por $\mathrm{kg}$ de produto (níveis mínimos de garantia): vitaminas: A 800.000 UI, B12 1.000mg, D3 2.000.000 UI, E $15.000 \mathrm{mg}$, K3 2.000mg, B2 $4.000 \mathrm{mg}$, B6 $1.000 \mathrm{mg}$, niacina $19.900 \mathrm{mg}$, ácido pantotênico $350 \mathrm{mg}$, ácido fólico $200 \mathrm{mg}$, selênio $2.500 \mathrm{mg}$, antioxidante $100.000 \mathrm{mg}$. 
As aves foram submetidas a um programa de luz de $16 \mathrm{~h} \mathrm{dia}^{-1}$. Diariamente, foi anotada a temperatura máxima e mínima do galpão. Foram avaliados o consumo de ração (g ave $\mathrm{dia}^{-1}$ ), conversão alimentar ( $\mathrm{kg}$ de ração $\mathrm{kg}^{-1}$ de massa de ovos) e peso médio dos ovos (g), efetuando-se a pesagem das rações e dos ovos ao final de cada semana, obtendo-se ao final do período experimental as médias de consumo, conversão alimentar e peso médio dos ovos referentes às três semanas avaliadas (ciclo ou período experimental). Os ovos foram coletados diariamente (às $12 \mathrm{~h}$ e às $15 \mathrm{~h}$ ) para determinação da produção de ovos (\% de postura ave $\left.^{-1} \mathrm{dia}^{-1}\right)$, anotando-se os ovos trincados, quebrados e anormais, sem casca e de casca mole. Nos últimos três dias de cada ciclo, foram avaliadas a gravidade específica, a porcentagem e espessura da casca e a porcentagem relativa de peso dos ovos armazenados por sete dias em relação ao ovo fresco. A gravidade específica foi obtida por imersão dos ovos em diferentes soluções salinas, com densidades de 1,$066 ; 1,070 ; 1,074 ; 1,078$; 1,$082 ; 1,086 ; 1,090 ; 1,094 ; 1,098$ e $1,102 \mathrm{~g} \mathrm{~mL}^{-1}$. As soluções salinas foram ajustadas com a utilização de um densímetro de petróleo, sendo calibradas periodicamente. Após a determinação da gravidade específica, dois ovos foram coletados, pesados e quebrados.

As cascas foram lavadas em água corrente, secas em temperatura ambiente por $48 \mathrm{~h}$ e pesadas em balança analítica, para determinação do peso da casca e, posteriormente, cálculo da porcentagem de casca. A espessura da casca do ovo foi obtida com auxílio de um micrômetro digital (Mitutoyo®), tomando-se quatro medidas na região central da casca, em que há maior homogeneidade da distribuição dos cristais de carbonato de cálcio. Foi realizada a determinação da porcentagem relativa do peso de dois ovos referentes a cada parcela durante o período de armazenagem de sete dias, em temperatura ambiente, em relação ao peso do ovo no dia da postura. A média da temperatura da sala onde os ovos foram armazenados foi aferida e anotada diariamente, de forma a avaliar a possível influência negativa do período de armazenamento de sete dias sobre a qualidade interna dos ovos. Os dados foram submetidos à análise de variância utilizando os recursos do programa computacional SISVAR (Ferreira, 1998) e as médias comparadas pelo teste SNK a $5 \%$ de probabilidade.

\section{RESULTADOS E DISCUSSÕES}

Não houve interação significativa $(P>0,05)$ entre tratamentos e períodos experimentais para as variáveis, produção de ovos, consumo de ração, conversão alimentar, peso médio dos ovos, perdas de ovos e peso específico (Tab. 2). Esses resultados estão de acordo com os encontrados por Liebert et al. (2005) que, ao suplementarem dietas para poedeiras com $300 \mathrm{FTU}$ de fitase, não obtiveram melhorias significativas nas variáveis de desempenho citadas em curto e longo prazo. No entanto, Keshavarz (2003) observou que houve redução no consumo de ração quando as aves receberam dieta com baixos teores de fósforo disponível $(0,2$ e $0,1 \%)$ e que o consumo foi restabelecido com a suplementação de fitase na ração (150 ou $300 \mathrm{FTU}$ ). Da mesma forma, Wu et al. (2006) observaram que a redução do fósforo disponível da dieta (de $0,38 \%$ para 0,26 e $0,11 \%$ ) provocou redução no consumo de ração. Os mesmos autores observaram que a adição de fitase às rações melhorou o consumo, embora ainda tenha ficado abaixo dos valores obtidos em aves que receberam a dieta controle.

Não houve efeito significativo $(\mathrm{P}>0,05)$ dos tratamentos experimentais sobre a produção de ovos, consumo de ração, peso médio dos ovos, perdas de ovos e peso específico. Resultados semelhantes são demonstrados por Ceylan et al. (2003), em que a adição de fitase às dietas de poedeiras, em substituição ao fósforo inorgânico, não alterou o desempenho das mesmas. Esses resultados suportam o conceito de que a fitase é eficaz em melhorar a disponibilidade de fósforo e que, assim, o nível de fósforo em dietas de poedeiras pode ser reduzido quando houver suplementação dessa enzima. No entanto, Francesch et al. (2005) observaram melhor porcentagem de postura em poedeiras alimentadas com rações à base de milho, contendo $0,11 \%$ de $\mathrm{Pd}$ e suplementadas com fitase $(150,300$ e 450 FTU de fitase $\mathrm{kg}^{-1}$ de ração), em comparação aos resultados obtidos em aves alimentadas com $0,32 \%$ de Pd.

Somente houve efeito significativo dos tratamentos sobre a conversão alimentar por massa de ovo no qual o tratamento 5 (Ração suplementada com 100 $\mathrm{g} \mathrm{t}^{-1}$ de carboidrases e $30 \mathrm{~g} \mathrm{t}^{-1}$ de fitase) apresentou o melhor resultado. Isso indica que a inclusão de enzimas no T5 (matriz incompleta para fitase valorizando somente $\mathrm{Ca}$ e $\mathrm{P}$ ) em comparação com o T4 (Ração suplementada com $100 \mathrm{~g} \mathrm{t}^{-1} \mathrm{de}$ carboidrases e $30 \mathrm{~g} \mathrm{t}^{-1}$ de fitase) proporcionou melhora nesse índice zootécnico. 
Tabela 2. Produção de ovos (PO), consumo de ração (CR), conversão alimentar por massa de ovos (CAMO), peso médio dos ovos (PMO), perdas de ovos (PER), gravidade específica dos ovos (GE) de poedeiras leves Bovans White alimentadas com dietas experimentais no período de 35 a 50 semanas de idade

\begin{tabular}{ccccccl}
\hline & \multicolumn{7}{c}{ Tratamentos } \\
\cline { 2 - 7 } Variáveis & $\mathrm{T} 1(\mathrm{CP})$ & $\mathrm{T} 2$ & $\mathrm{~T} 3$ & $\mathrm{~T} 4$ & $\mathrm{~T} 5$ & $\mathrm{CV}(\%)$ \\
\hline PO (\%/ave/dia) & 96,99 & 97,04 & 96,61 & 96,86 & 96,80 & 1,30 \\
CR (g/ave) & 112,32 & 112,08 & 112,30 & 113,87 & 111,58 & 4,39 \\
CAMO (g/g) & $1,87 \mathrm{ab}$ & $1,88 \mathrm{ab}$ & $1,89 \mathrm{ab}$ & $1,91 \mathrm{c}$ & $1,86 \mathrm{a}$ & 3,73 \\
PMO (g) & 61,83 & 61,46 & 61,47 & 61,60 & 61,82 & 3,18 \\
PER (\%/ave/dia) & 0,079 & 0,090 & 0,106 & 0,104 & 0,123 & 119,02 \\
GE (g/mL) & 1,090 & 1,089 & 1,090 & 1,089 & 1,089 & 0,20 \\
\hline
\end{tabular}

${ }^{1}$ Médias seguidas de letras diferentes na linha diferem estatisticamente pelo teste $\mathrm{SNK}(\mathrm{P}<0,05)$.

Houve efeito significativo $(\mathrm{P}<0,01)$ sobre a produção de ovos entre os períodos (Tab. 3), ocorrendo diminuição com o avançar da idade das aves, fato comumente observado em outras pesquisas, já que normalmente a produção diminui a idade das aves (Silva et al., 2008; Viana et al., 2009).
De acordo com os resultados obtidos, observamse efeitos sobre o consumo de ração $(\mathrm{P}<0,01)$, sendo maior nos três primeiros períodos experimentais, seguido de decréscimo no quarto, voltando a aumentar no quinto.

Tabela 3. Produção de ovos (PO), consumo de ração (CR), conversão alimentar por massa de ovos (CAMO), peso médio dos ovos (PMO), perda dos ovos (PER) e peso específico dos ovos (PE) por período experimental em poedeiras Bovans White submetidas a diferentes rações experimentais no período de 35 a 50 semanas de idade

\begin{tabular}{|c|c|c|c|c|c|c|}
\hline \multirow[t]{2}{*}{ Períodos } & \multicolumn{6}{|c|}{ Variáveis } \\
\hline & $\begin{array}{c}\mathrm{PO} \\
{\text { (\%/ave/dia })^{1}}^{1}\end{array}$ & $\begin{array}{l}\text { CR } \\
(\mathrm{g})^{1}\end{array}$ & $\begin{array}{l}\text { CAMO } \\
(\mathrm{g} / \mathrm{g})^{1}\end{array}$ & $\begin{array}{l}\text { PMO } \\
(\mathrm{g})^{1}\end{array}$ & $\begin{array}{c}\text { PER } \\
\text { (\%/ave/dia) }^{1}\end{array}$ & $\begin{array}{c}\mathrm{PE} \\
(\mathrm{g} / \mathrm{mL})^{1}\end{array}$ \\
\hline I & $98,22 \mathrm{a}$ & $112,00 \mathrm{c}$ & $1,891 \mathrm{~b}$ & $60,68 \mathrm{c}$ & $0,083 \mathrm{~b}$ & $1,091 \mathrm{a}$ \\
\hline II & $98,24 \mathrm{a}$ & $115,47 \mathrm{a}$ & $1,922 \mathrm{c}$ & $61,20 \mathrm{~b}$ & $0,065 \mathrm{~b}$ & $1,088 \mathrm{~b}$ \\
\hline III & $97,03 \mathrm{~b}$ & $114,06 \mathrm{~b}$ & $1,910 \mathrm{ab}$ & $61,57 \mathrm{~b}$ & $0,093 \mathrm{~b}$ & $1,089 \mathrm{~b}$ \\
\hline IV & $95,83 \mathrm{c}$ & $107,83 \mathrm{~d}$ & $1,766 \mathrm{a}$ & $63,21 \mathrm{a}$ & $0,190 \mathrm{a}$ & $1,090 \mathrm{a}$ \\
\hline V & $94,97 \mathrm{~d}$ & $112,78 \mathrm{c}$ & $1,932 \mathrm{c}$ & $61,51 \mathrm{~b}$ & $0,070 \mathrm{~b}$ & $1,089 \mathrm{~b}$ \\
\hline $\mathrm{CV}(\%)$ & 0,93 & 2,40 & 2,60 & 1,39 & 89,76 & 0,12 \\
\hline
\end{tabular}

${ }^{1}$ Médias seguidas de letras diferentes na coluna diferem estatisticamente pelo teste $\mathrm{SNK}(\mathrm{P}<0,01)$.

Observou-se efeito da CAMO entre os períodos $(\mathrm{P}<0,05)$, em que os piores resultados foram nos períodos II, III e $\mathrm{V}$, que apresentaram a pior CA. Como essa variável depende das variáveis produção de ovos, consumo de ração e peso médio dos ovos, observa-se que a melhor conversão alimentar ocorreu no período IV, no qual houve o menor consumo de ração e o maior peso médio dos ovos.

Foi observado efeito significativo $(\mathrm{P}<0,01)$ entre períodos experimentais sobre o peso médio dos ovos, com maior peso no segundo período, fato associado ao aumento do consumo de ração. Esse maior consumo de ração e maior peso dos ovos proporcionaram piora da conversão alimentar no segundo período. Em estudos com poedeiras leves e semipesadas, recebendo dietas suplementadas com xilanase e fitase, Silversides et al. (2006) também confirmaram aumento do peso médio dos ovos com o avançar da idade das aves. Segundo Flemming (2005), outro fator relacionado ao aumento do peso médio dos ovos é a estreita correlação entre a produção e o tamanho dos ovos, de modo que uma redução na taxa de postura aumenta o peso dos ovos, indicando tendência de as poedeiras manterem a massa de ovo produzida, o que observamos com o avanço dos períodos.

Sobre a variável perda de ovos, houve efeito nos períodos $(\mathrm{P}<0,01)$, sendo observada maior porcentagem de perdas/ave/dia no período IV, 
permanecendo semelhantes nos demais períodos. Lim et al. (2003), em estudo com poedeiras, determinaram melhora na qualidade da casca dos ovos quando suplementaram a dieta com 300 FTU de fitase, em virtude da redução de ovos quebrados e de casca mole. Os valores de peso específico variaram pouco dentro dos períodos $(\mathrm{P}<0,01)$, obtendo menor valor nos períodos dois, três e cinco.

\section{CONCLUSÃO}

Os tratamentos controle e a suplementação de carboidrases e fitase em dietas valorizadas para EMAn, aminoácidos, fósforo e cálcio para poedeiras da linhagem Bovans White garantiram o desempenho satisfatório no que diz respeito à produção, peso e perdas dos ovos e consumo de ração. A utilização de carboidrases em dietas formuladas com a matriz completa da enzima fitase não se mostrou eficiente para a variável conversão alimentar por massa de ovos, porém a utilização de carboidrases em dietas formuladas com a matriz incompleta de fitase apresentou melhora significativa nessa variável.

\section{REFERÊNCIAS}

CEYLAN, N.; SCHEIDELER, S.E.; STILBORN, H.L. High available phosphorus corn and phytase in layer diets. Poultry Sci., v.82, p.789-795, 2003.

CONTE, A.J.; TEIXEIRA, A.S.; FIALHO, E.T. et al. Efeito da fitase e xilanase sobre o desempenho e as características ósseas de frangos de corte alimentados com dietas contendo farelo de arroz. Rev. Bras. Zootec., v.32, p.1147-1156, 2003.

FERREIRA, D.N. Sistema de análise estatística para dados balanceados. Lavras: UFLA/DEX/Sisvar, 1998.

FLEMMING, E. Controlling late egg size. World Poultry, v.21, p.14-15, 2005.

FRANCESCH, M.; BROZ, J.; BRUFAU, J. Effects of an experimental phytase on performance, egg quality, tibia ash content and phosphorus bioavailability in laying hens fed on maize or barley-based diets. $\mathrm{Br}$. Poultry Sci., v.46, p.340-348, 2005.

KESHAVARZ, K. The effect of different levels of nonphytate phosphorus with and without phytase on the performance of four strains of laying hens. Poultry Sci., v.82, p.71-91, 2003.
LIEBERT, F.; HTOO, J.K.; SUNDER, A. Performance and Nutrient Utilization of Laying Hens Fed Low-Phosphorus Corn-Soybean and WheatSoybean Diets Supplemented with Microbial Phytase. Poultry Sci., v.84, p.1576-1583, 2005.

LIM, H.S.; NAMKUNG, H.; PAIK, I.K. Effects of phytase supplementation on the performance, egg quality, and phosphorous excretion of laying hens fed different levels of dietary calcium and nonphytate phosphorous. Poultry Sci., v.82, p.92-99, 2003.

LIU, G.W.Z.; BRYANT, M.M.; ROLAND, D.A. Comparison of Natuphos and Phyzyme as Phytase Sources for Commercial Layers Fed Corn-Soy Diet. Poultry Sci., v.85, p.64-69, 2006.

MAZZUCO, H. Ações sustentáveis na produção de ovos. Rev. Bras. Zootec., v.37, p.230-238, 2008.

PLUMSTEAD, P.W.; ROMERO-SANCHEZ, H.; MAGUIRE, R.O. et al. Effects of phosphorus level and phytase in broiler breeder rearing and laying diets on live performance and phosphorus excretion. Poultry Sci., v.86, p.225-231, 2007.

PRODUCT Performance - Bovans White. A Hendrix Genetics Company. 2006, 7p.

ROSTAGNO, H.S.; ALBINO, L.F.T. DONZELE, J.L. et al. Tabelas brasileiras para aves e suínos: composição de alimentos e exigências nutricionais. Viçosa, MG: Universidade Federal de Viçosa, 2005. 186p.

SILVA, L.M.; GERALDO, A.; VIEIRA FILHO, J. A. et al. Associação de carboidrases e fitase em dietas valorizadas e seus efeitos sobre o desempenho e qualidade dos ovos de poedeiras semi-pesadas. I Semana de Ciência e Tecnologia do CEFET Bambuí. Bambuí - MG, 2008.

SILVERSIDES, F.G.; SCOTT, T.A.; KORVER, D.R. et al. A Study on the Interaction of Xylanase and Phytase Enzymes in Wheat-Based Diets Fed to Commercial White and Brown Egg Laying Hens. Poultry Sci., v.85, p.297-305, 2006.

SNOW, J.L.; DOUGLAS, J.L.S.M.W.; PARSONS, C.M. Phytase Effects on Amino Acid Digestibility in Molted Laying Hens. Poultry Sci., v.82, p.474-477, 2003.

VIANA, M.T.S.; ALBINO, L.F.T.; ROSTAGNO, H.S. et al. Efeito da suplementação de fitase no metabolismo de nutrientes e o desempenho de poedeiras. Rev. Bras. Zootec., v.38, p.1074-1080, 2009.

WU, G.; LIU, Z.; BRYANT, M.M.; ROLAND, D.A. Comparison of natuphos and phyzyme as phytase sources for commercial layers fed corn-soy diet. Poultry Sci., v.85, p.64-79, 2006. 